\title{
A Comparative Study of "Subtitled" vs. "Auditory" Documentaries Comprehension among Persian Speakers of English
}

\author{
Masoud Raee Sharif, PhD (Corresponding author) \\ Department of foreign Languages, Payarn Noor University of Teheran - Iran \\ E-mail: mraeesharif@gmil.com \\ Maryam Ebrahimian \\ E-mail: maryam.ebrahimian@yahoo.com
}

Received: 29-12- 2012

doi:10.7575/aiac.ijalel.v.2n.2p.185
Accepted: 29-01- 2013

Published: 01-03- 2013

URL: http://dx.doi.org/10.7575/aiac.ijalel.v.2n.2p.185

\begin{abstract}
This study set out to compare the effect of modality of presentation (subtitled vs. auditory) on the retention of verbal content of documentary films among Iranian EFL students. To this end, 60 participants (30 male and 30 female students) of homogeneous English proficiency were volitionally assigned to one of the two experimental conditions: English soundtrack with no subtitles (ESONSU), no soundtrack with English subtitles (NSOESU). The sample was asked to watch five five-minute documentary clips with the presentation format varied in terms of the verbal information, which was alternatively given in soundtracks and subtitles. Thus, while one group was presented with subtitled documentary excerpts, the other group watched the same clips with the sound tracks. Comparison of the two groups on Mann-Whitney $U$ test illustrated that there is not any significant difference between the rate of comprehension of subtitled documentaries as opposed to audible documentaries. However, females were found to outperform their male counterparts in both subtitled documentaries comprehension (median $=20$ vs. male median $=13$ ) and audible documentary comprehension (females' median $=20.5$ vs. males' median $=13.5$ ).
\end{abstract}

Key words: Listening comprehension, Reading comprehension, Subtitles

\section{Introduction}

Today's world is undoubtedly "a visually oriented one. Films and videos capture audiences not only in the field of entertainment, but also in the business of corporate world and education" (Stoller 1990:10, cited in Canning-Wilson 2000). The incorporation of video in foreign language instruction has recently benefitted from the "proliferation of subtitled material that provides learners with more opportunity for auditory discrimination through comparison of subtitles and audio for establishing connection between words and images; for checking and reinforcing listening comprehension, for improving vocabulary acquisition and reading ability with the help of verbatim subtitles" (Spanos and Smith 1990, cited in Chang, 2003, p.162). According to Winke, Gass and Sydorenko. (2010), with a greater emphasis on technology in language classrooms, the use of captioning will undoubtedly increase in importance and frequency. If this is to happen, appropriate research will need to increase in future years lest we introduce a pedagogical tool without fully understanding its implications.

With this in mind, the present study investigates the influence of modes of presentation (muted vs. auditory documentaries) on the rate of listening comprehension among Iranian EFL students. So far, as Hinkin (2009) explains, "ample research has been carried out on audiovisual material enhanced with subtitles, each attempting to explore a different aspect of subtitling on second/foreign language learning”. However, as many language teaching specialists such as Hinkin (ibid) have pointed out "previous research has primarily focused on the influence of subtitles on attention and the effectiveness of subtitles for promoting foreign language acquisition. Some studies have also investigated comprehension of subtitled movies and television" (paragraph 2). However, "despite the obvious obsession people have with viewing movies, psychological research investigating the influence of subtitles on movie viewing is limited" (p.1 paragraph 1).

A video stream is actually a semiotic composition of four channels: the verbal auditory channel (dialogue, background voices, and lyrics), the non-verbal auditory channel (natural sounds, sound effects, and music), the verbal visual channel: subtitles and any writing in the film, and finally the non-verbal visual channel (composition of the images, camera positions, movements and their editing)" (Baker, 1998). In bilingual situations, like the one in the present study, the listener relies on two separate verbal systems related by associative connections. In subtitled films, these three independent systems are interconnected and presented simultaneously. This may lead to better processing and recall because of the additive effects of both image and translation. However, further investigation of the influence of 
simultaneous presentations of multiple information channels is required. In particular, researchers must understand how visual and auditory stimuli, presented simultaneously, affect each other in terms of working memory (Hinkin, 2009).

It is worth mentioning that "while working memory studies have profoundly influenced the development of new cognitive theories, including the Dual-Processing Theory (Mayer \& Moreno, 1998 cited by Hinkin,2009, p. 3), limited research has investigated the effects of subtitled messages on multimedia comprehension" (Hinkin, 2009). Besides, subtitling has received little attention from experimental psychology and communication studies. For this reason, practical applications of subtitling rely more on conventional rules of thumb than on validated empirical guidelines. Research in this area can, therefore, have significant applied value (Prego et al., 2010, p.245), which is why the present study is of paramount value.

The purpose of this study is twofold: first to determine which listening situation (foreign language soundtrack or foreign language subtitles) is more conducive to better comprehension of English documentaries; second, to investigate which gender of females or males, under similar conditions, would comprehend which situation (foreign language soundtrack or foreign language subtitles) better. In other words, the present study aims to answer the following questions:

1. Is there any difference in the comprehension of subtitled documentaries vs. audible documentaries?

2. Is there any difference in the comprehension of subtitled documentaries by male and female language learners?

3. Is there any difference in the comprehension of audible documentaries by male and female language learners?

\section{This Study}

In order to conduct this research, two groups of male and female students consisting of 30 males from Allameh Helli Gifted Students High School and 30 females from Farhange Amoozesh Institute aged between 16-18 years old were chosen to participate in this study. Based on their own volition, they were then assigned to one of the two experimental conditions: English soundtrack with no subtitles (ESONSU), no soundtrack with English subtitles (NSOESU). A customized PET test (C-PET) as well as a set of teacher-made comprehension tests were used to elicit the required data. The former was utilized to ascertain the homogeneity of the sample. The K-R21 reliability index for this altered test stood at .74, rendering it reliable for the purpose intended.

Based on the C-PET, it was found that the two groups of students were homogeneous in terms of general English proficiency prior to the main study. The ultimate 30 students in each group then stood as the final sample.

In addition to the C-PET, a comprehension test comprising 47 multiple choice questions was also administered to the sample after watching the documentary films to see in which situation and by which gender more comprehension is achieved.

\section{Procedure}

After ensuring the homogeneity, the sample was assigned to 2 groups (in 4 classes, 2 in each situation of either ESONSU or NSOESU on the basis of their preference to watch either the subtitled documentaries or the audible documentaries. The experiment continued for two sessions over two weeks. In each session, the students watched segments of one episode twice for about 30 minutes each time. Before presenting the film, the researcher would brief the sample on what they were going to watch. She would brainstorm the learners by asking questions about the story of the upcoming documentary. While presenting the film, the researcher would remain in the classroom with the learners to observe their reactions, and to pause and rewind if necessary. After watching the film, the researcher would ask for feedback from the viewers.

In each session, the researcher presented segments (of 5 minute documentaries) from 3 episodes of the English documentary pack entitled "Planet Earth" to the sample. After each presentation, the participants were asked to complete the comprehension test on the same presentations. After they had completed the comprehension tests, the participants were informed of the purpose of the experiment and given the opportunity to ask questions related to the material. Finally the participants were thanked for their participation and dismissed. The experimental procedure took approximately 45 minutes from welcome to dismissal in each session.

\section{Data Analysis}

Following the administration of the comprehension test, which consisted of 47 multiple choice items based on the information provided in the documentary clips, the student's performance on the comprehension test was scored. Each correct answer carried one point. To gain insight into the characteristics of the two groups, the scores obtained were plugged into the Mann-Whitney U tests for comparison of the results.

\subsection{Placement Homogeneity (PET)}

In order to ascertain the homogeneity of the two groups, the researcher administered two sections of the Preliminary English Test (PET), reading and listening, to the participants. In order to calculate and compare the mean scores of the participants on PET, the present researcher also ran an Independent Sample t-test to prove that the two students enjoyed the same level of general language proficiency prior to the main study. 
Table 1. Descriptive Statistics Proficiency Test by Gender

\begin{tabular}{|l|c|c|c|c|}
\hline Group & $\mathrm{N}$ & Mean & Std. Deviation & Std. Error Mean \\
\hline Female & 39 & 31.23 & 6.741 & 1.079 \\
\hline Male & 39 & 31.05 & 7.071 & 1.132 \\
\hline
\end{tabular}

Table 2. Independent t-test Proficiency Test by Gender

\begin{tabular}{|c|c|c|c|c|c|c|c|c|c|}
\hline & \multicolumn{2}{|c|}{$\begin{array}{l}\text { Levene's Test for } \\
\text { Equality of Variances }\end{array}$} & \multicolumn{7}{|c|}{ t-test for Equality of Means } \\
\hline & \multirow[t]{2}{*}{$\mathrm{F}$} & \multirow[t]{2}{*}{ Sig. } & \multirow[t]{2}{*}{$\mathrm{T}$} & \multirow[t]{2}{*}{ Df } & \multirow[t]{2}{*}{$\begin{array}{l}\text { Sig. (2- } \\
\text { tailed) }\end{array}$} & \multirow[t]{2}{*}{$\begin{array}{c}\text { Mean } \\
\text { Difference }\end{array}$} & \multirow[t]{2}{*}{$\begin{array}{l}\text { Std. Error } \\
\text { Difference }\end{array}$} & \multicolumn{2}{|c|}{$\begin{array}{l}\text { 95\% Confidence } \\
\text { Interval of the } \\
\text { Difference }\end{array}$} \\
\hline & & & & & & & & Lower & Upper \\
\hline $\begin{array}{l}\text { Equal variances } \\
\text { assumed }\end{array}$ & .057 & .812 & .115 & 76 & 909 & 179 & 1.564 & -2.936 & 3.295 \\
\hline $\begin{array}{l}\text { Equal variances not } \\
\text { assumed }\end{array}$ & & & .115 & 75.828 & .909 & .179 & 1.564 & -2.936 & 3.295 \\
\hline
\end{tabular}

It should be noted that the assumption of homogeneity of variances is met (Levene's $\mathrm{F}=.057, \mathrm{P}=.912>.05)$. The first row of Table 2, i.e. "Equal variances assumed" is reported.

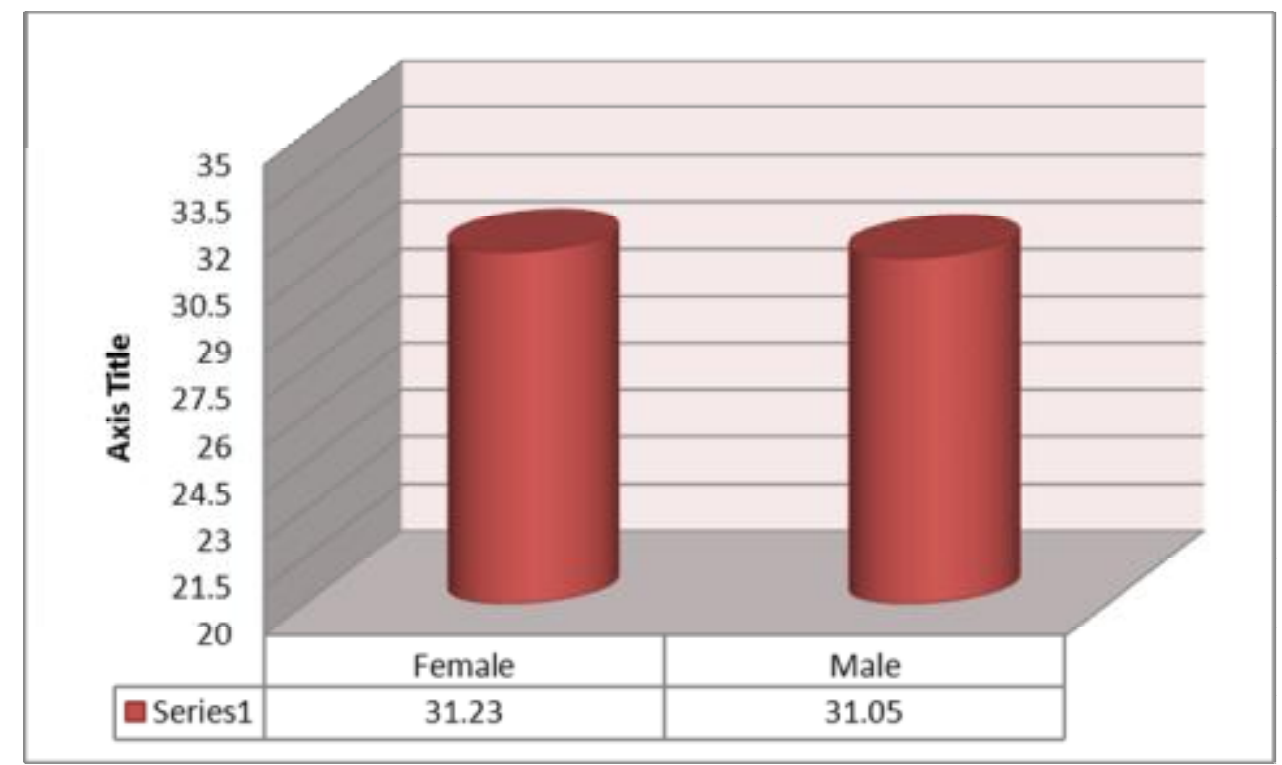

Graph 1. Proficiency Test by Gender

\subsection{Statistical Analysis}

In order to test the Research Hypotheses, the following statistical techniques were utilized:

1. Independent t-test Proficiency Test by Gender was performed to check the homogeneity of the two groups at the outset of the experiment.

2. Mann-Whitney $U$ test was run to probe the research questions

\subsection{Normality Test (by Types of Movies)}

The students' scores on the comprehension test did not enjoy normal distribution. As displayed in Table 3 the ratios of skewedness indices over their respective standard errors are beyond the acceptable ranges of +/- 1.96.

Table 3. Normality Test (by Types of Movies)

\begin{tabular}{|l|c|c|c|c|c|c|}
\hline \multirow{2}{*}{ SOURCE } & \multicolumn{3}{|c|}{ Skewedness } & \multicolumn{3}{c|}{ Kurtosis } \\
\cline { 2 - 8 } & Statistic & Std. Error & Normality & Statistic & Std. Error & Normality \\
\hline AUDIO & 1.299 & .403 & 3.22 & 1.050 & .788 & 1.33 \\
\hline VISUAL & 1.325 & .403 & 3.28 & .544 & .788 & .690 \\
\hline
\end{tabular}


Histogram 1 graphically displays the non-normality of the data. That is why the non-parametric equivalent of independent $\mathrm{t}$-test, i.e. Mann-Whitney $\mathrm{U}$ test is run to probe the research questions.

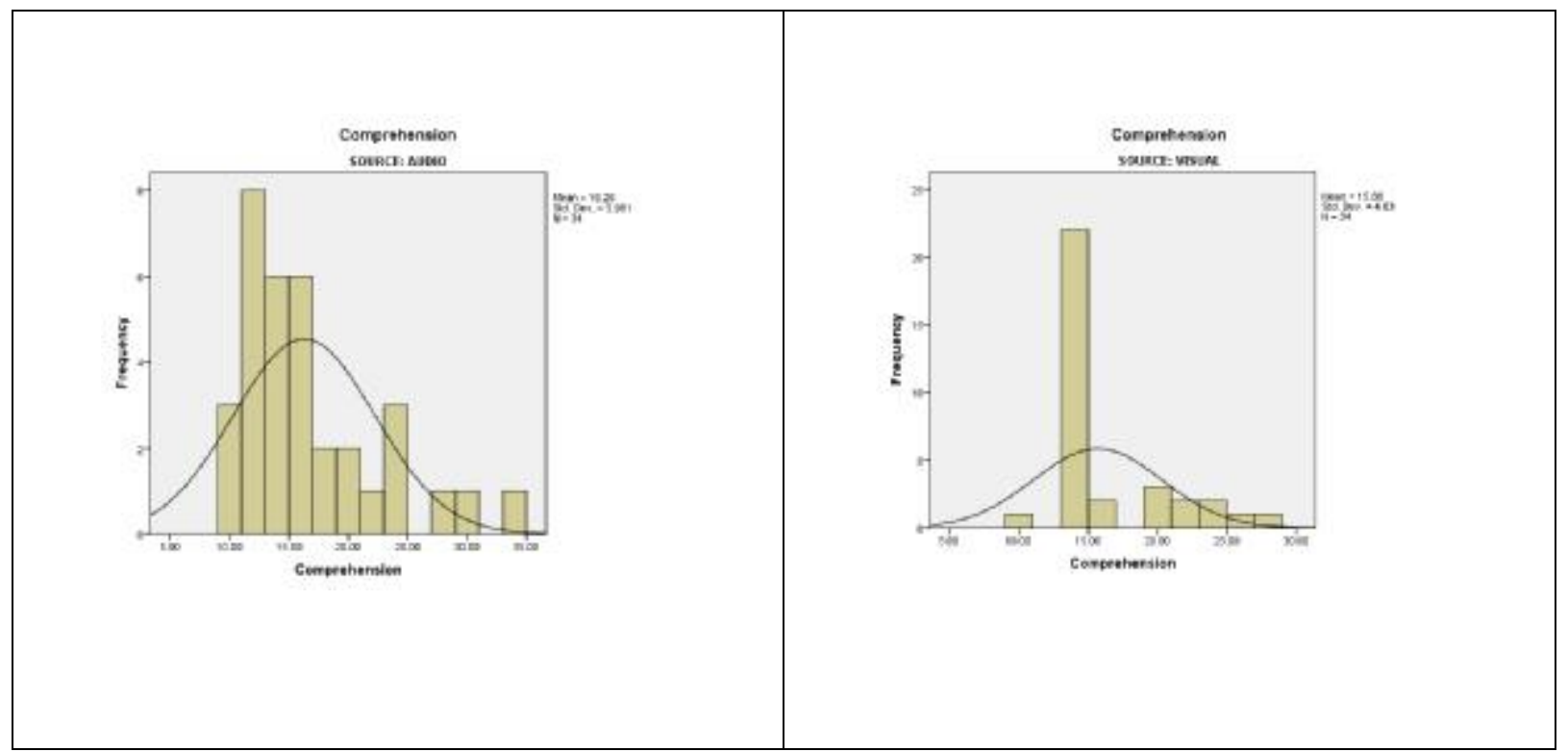

Histogram 1. Comprehension (by Types of Movies)

\subsection{Normality Test (by Gender)}

The students' scores on the comprehension test do not enjoy normal distribution. As displayed in Table 4 the ratios of $\mathrm{s}$ skewedness indices over their respective standard errors are beyond the acceptable ranges of $+/-1.96$.

Table 4. Normality Test (by Gender)

\begin{tabular}{|l|c|c|c|c|c|c|}
\hline \multirow{2}{*}{ SOURCE } & \multicolumn{3}{|c|}{ Skewedness } & \multicolumn{3}{c|}{ Kurtosis } \\
\cline { 2 - 7 } & Statistic & Std. Error & Normality & Statistic & Std. Error & Normality \\
\hline AUDIO & .174 & .464 & .375 & -.362 & .902 & .40 \\
\hline VISUAL & 2.619 & .361 & 7.25 & 10.408 & .709 & 14.67 \\
\hline
\end{tabular}

Histogram 2 graphically displays the non-normality of the data. That is why the non-parametric equivalent of independent $t$-test, i.e. Mann-Whitney $U$ test is run to probe the research questions targeting male and female performance on the comprehension test.

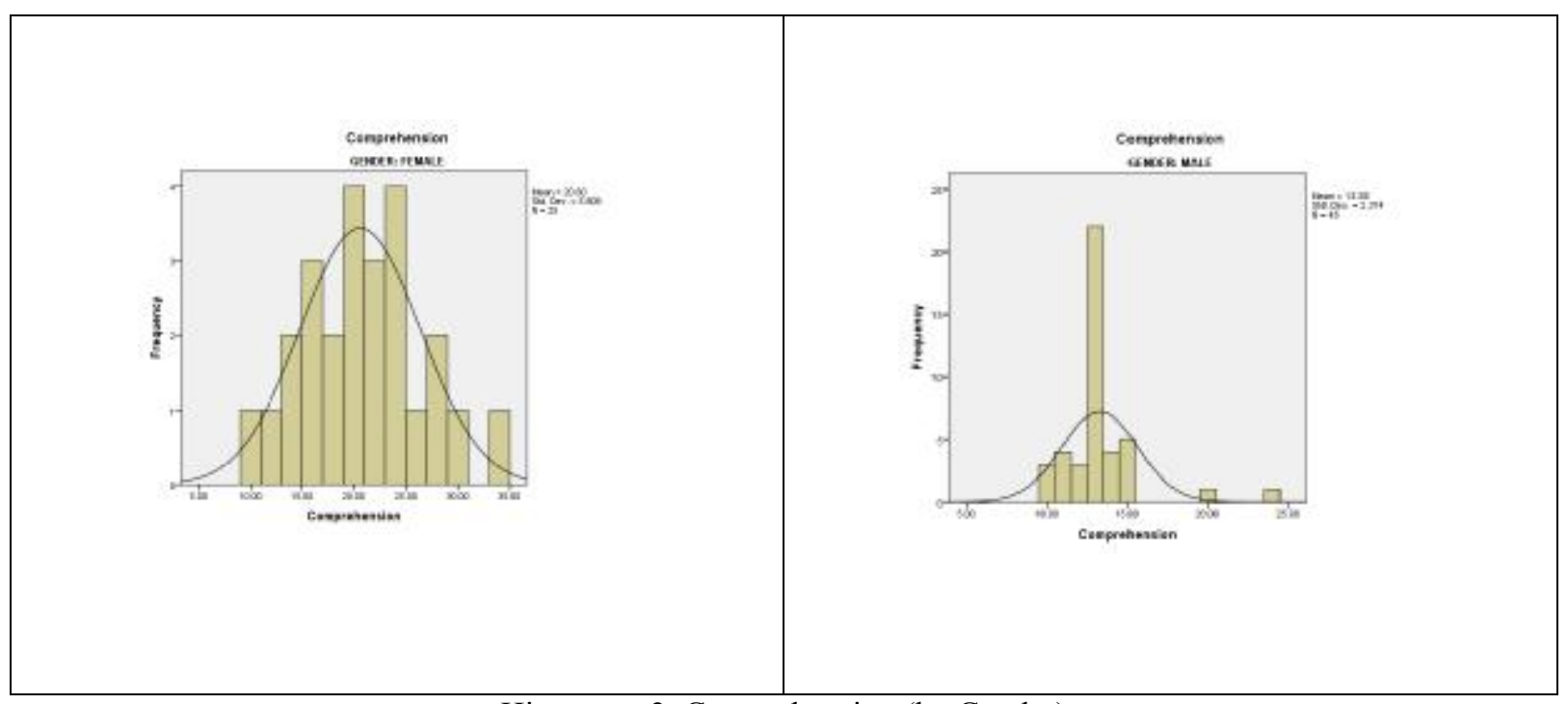

Histogram 2. Comprehension (by Gender)

\section{Results}


As stated earlier, the current study was conducted to answer the following questions:

1. Is there any difference in the comprehension of subtitled documentaries vs. audible documentaries?

2. Is there any difference in the comprehension of subtitled documentaries by male and female language learners?

3. Is there any difference in the comprehension of audible documentaries by male and female language learners?

As for our first research hypothesis reading "is there any difference in the comprehension of subtitled documentaries vs. audible documentaries?" the sample did not enjoy normal distribution, so we had to resort to the non-parametric MannWhitney $U$ test to probe the answer to this research question. The above mentioned histogram depicts the rate of comprehension in our sample by gender.

Based on the results displayed in Table 5 below, it can be concluded that there is no significant difference between the comprehension of subtitled documentaries (Median $=13$ ) versus audible documentaries (Median = 14.5). Thus, our first null-hypothesis based on the first research question was supported. This means that in the current study reading the verbal information in the subtitles was not found to be more efficient than listening to the soundtracks. The performance of all students who watched the documentary movie clips mute while they read subtitles did not show greater superiority over that of those who watched the same movie clips and listened to the soundtracks.

Table 5. Mann-Whitney U Test Comprehension (Audible vs. Subtitled)

\begin{tabular}{|l|l|}
\hline & Pretest \\
\hline Mann-Whitney U & 566.000 \\
\hline Wilcoxon W & 1161.000 \\
\hline Z & -.151 \\
\hline Sig. (2-tailed) & .880 \\
\hline Median (Subtitled) & 13 \\
\hline Median (Audible) & 14.5 \\
\hline
\end{tabular}

As for our second research question, which reads "is there any difference in the comprehension of subtitled documentaries by male and female language learners?" again a Mann-Whitney U test was run to compare the median scores of the male and female listeners on the comprehension test of subtitled documentaries. Based on the results displayed in Table 6, it can be concluded that there is a significant difference between the rate of comprehension of subtitled documentaries by females (Median $=20$ ) and that of males (Median =13). Thus, it can be concluded that the $2^{\text {nd }}$ null-hypothesis based on the $2^{\text {nd }}$ research question is rejected, meaning that when Iranian female EFL students are given muted subtitled documentaries to comprehend, they can significantly outperform their male counterparts.

Table 6. Mann-Whitney U Test Comprehension (Male vs. Female Subtitled Movies)

\begin{tabular}{|l|l|}
\hline Statistic & Pretest \\
\hline Mann-Whitney U & 31.500 \\
\hline Wilcoxon W & 262.500 \\
\hline Z & -4.360 \\
\hline Sig. (2-tailed) & .000 \\
\hline Median (Female) & 20 \\
\hline Median (Male) & 13 \\
\hline
\end{tabular}

As for our third research hypothesis which reads is there any difference in the comprehension of audible movies by male vs. female language learners, again, a Mann-Whitney U test was run to compare the median scores of male vs. female language learners on audible documentaries in order to assess the third hypothesis. Based on the results displayed in Table 7, it can be concluded that there is a significant difference between the comprehension of females $($ Median $=20.5)$ and males (Median =13.5) in the audible documentaries. Thus, it can be concluded that the third nullhypothesis is rejected, implying that female EFL students performed better on audible movies than their male counterparts.

Table 7. Mann-Whitney U Test Comprehension (Male vs. Female Audible Movies)

\begin{tabular}{|l|l|}
\hline & Pretest \\
\hline Mann-Whitney U & 35.500 \\
\hline Wilcoxon W & 288.500 \\
\hline$Z$ & -3.493 \\
\hline Sig. (2-tailed) & .000 \\
\hline Median (Female) & 20.5 \\
\hline Median (Male) & 13.5 \\
\hline
\end{tabular}




\section{Discussion}

The purpose of this study was to compare the utility and applicability of soundtracks as opposed to subtitles in the comprehension of documentary movies. This study was motivated by Lang's (1995), which compared auditory (soundtrack) and visual (subtitles) verbal information in relation to recognition abilities. Nevertheless, most of the existing literature in this area, as Lang (1995) describes it, is inconclusive since "limited research is done on recognition tests for combined visual-verbal information". Furthermore, the studies conducted before did not take into account gender differences. Considering that the research so far has not been conclusive, the need for further investigation is an important issue to be considered here.

As enumerated above, he present study had 3 primary questions to answer, based on which 3 null hypotheses were formed. As for the first null hypothesis (differences in the rate of comprehension of subtitled documentaries versus audible documentaries), evaluation of the data demonstrated that there is no significant difference between the rate of comprehension of subtitled documentaries as opposed to audible documentaries. Thus, it can be concluded that presentation format does not influence performance on recognition tests. In other words, it doesn't really matter whether people resort to subtitles or soundtracks for the comprehension of documentary movies. In this respect, however, our findings conflict earlier literature stating that reading verbal information in subtitles is more efficient than listening to the actual soundtrack, which is what most of the earlier literature points at. More specifically our results conflict Mayer's (1997) findings that "when presented with a combination of two visual inputs (pictures and text), observers [are] not able to focus their attention on both stimuli concurrently", which yields "less understanding compared to the presentation of a visual and oral stimulus concurrently". Moreover, Hinkin's (ibid) predictions which are based on Mayer and Moreno's (1998) dual-process theory stating that "when participants are instructed to answer questions about the verbal content of a movie clip, performance would be optimized if the verbal information is presented in the soundtrack and no verbal information is presented in the subtitles" is also in contradictions with the findings of the present study. The findings of the current study also did not confirm Tulving \& Thomson's (1973) principle of encoding specificity (cited by Hinkin, 2009.p.11), which expects performance on the verbal-only questions to be better than performance with verbal information in the soundtrack. Alternatively, our findings are also in contrast with Lang's (1995), where it was revealed that visually presented verbal information yields better performance on verbal recognition tasks than auditory verbal information.

To summarize, our overall results indicate that the idea that processing subtitled documentaries is easier for the listener than audible input does not necessarily hold true. For example, it contravenes D'Ydewalle et al.'s (1987 \& 1991), which suggests that reading verbal information is much easier than listening to the soundtrack because observers are able to read the subtitles faster than they can comprehend the actual words being spoken in the soundtrack. However, D'Ydewalle's study and explanation can hardly ring true in the case of the native language, where soundtrack is by far easier and more convenient to listen to than subtitles. In the case of the mother tongue, use of subtitles is only justified when hearing the audio is not possible or easy as in public places with a lot of noise.

The conflict between this and the previous studies could be attributed to a number of factors. First and foremost, the design of the present study, i.e. ex post facto, may have been inappropriate for this line of inquiry. In our work, the students did not receive any particular instruction or hands-on training prior to undergoing this study. They were just taken as they were and plugged into the study for data elicitation. Secondly, there could have been extraneous variables involved, which the researchers failed to detect and eradicate. Of other factors one could think of could be the research milieu or the contexts of such schools in Iran, which could have been different from those elsewhere in the world.

Another potential explanation could be that the methods of multimedia presentation used in the current study drastically differed from those of Mayer and Moreno (1998). The present study used movie clips, which can present highly dynamic scenes, whereas the bicycle pump scenes presented by Mayer and Moreno contained less action.

With regard to the second hypothesis in the present study, previous literature has not addressed gender specification with regard to comprehension in multimedia environment when subtitles are concerned specifically. It is to be mentioned that although pervious research has previously dealt with gender differences and reading comprehension performances of the participants, reading subtitles can not be regarded as a reading task.

With regard to our third null hypothesis, a potential reason for the poor performance of male students as opposed to their female counterparts may be related to a factor called field dependent/independent; a variable which the researchers did not consider in the present study. Yousefi (2011) investigated the relationship between field independent vs. field dependent cognitive styles and Iranian EFL learners' listening comprehension ability. An interesting result of her study was that gender has no relationship with the learners' listening ability, and although a slight difference is observed between field dependent boys' performance and field dependent girls' performance, it is not big enough to indicate any relationship between the two variables.

Nevertheless, the interaction of sex and cognitive style can have a relatively strong effect on the learners' listening comprehension ability. Accordingly, she concludes that there is a statistically significant difference between field dependence and field independence learners' performance on listening tests, with the field dependence style showing a relatively facilitative effect on this skill.

There could be physiological reasons for the superiority of female listeners as well. Researchers from Northwest Carolina found that the areas of the brain connected with language processing work faster in girls than in boys. This is mostly during language activities. Elsewhere it is found that girls show greater activity in the superior temporal gyrus. 
Girls also show greater activity in is the fusiform gruys found on the left side of the brain. This area helps students identify the spelling of words using visual modality (Halpern, 2000).

As stated earlier, our findings show that female participants performed better in both audio and subtitle situations. Therefore, one might be tempted to conclude that women are altogether better listeners than men. However, the results of research by Yousefi (2011) did not find any significant difference between Iranian EFL learners' listening comprehension ability and their gender. She maintains that if there is any relationship between these two factors, it has to do with field dependence vs. field independence dichotomy, meaning that if one gender shows any superiority over the other, it is because of the general tendency of the respective gender to be FD or FI. Otherwise, their pure comprehension capacities are similar.

Based on all that went above, one might ponder if women outperform men in listening comprehension, what is the state of affairs when it comes to speaking? Interestingly enough, there is ample body of literature pointing to the superior performance of women over men in speaking and altogether in all aspects of oral skills. Raee Sharif and Kiani Parsa (2009) found that between male and female speakers, the latter are comprehended much better than men, which implies that women are able to encapsulate their verbal message in a better way than men, and both men and women would comprehend them better.

There are some limitations in the present study which can be addressed in future studies. First, the study included only the Iranian EFL learners. More comprehensive work including other nationalities and/or SL learners will contribute to our understanding of the relationship between modality of presentation and comprehension ability in the multimedia context. Secondly, as with any scientific finding, replication is needed in different settings with diverse populations to increase the external validity. Also it is possible that a different type of listening test would yield different results. Another limitation of the current study is that only recognition measures were used. The participants in this study completed only one type of question, namely verbal only multiple-choice recognition questions. Other types of questions including: pictorial, verbal and combined formats can be used in future studies. Moreover, comparison of performances on pictorial questions across other presentation formats (than video) can also be another line of inquiry.

In prospective studies, comprehension tests can also incorporate free-recall measures to allow for comparisons between recognition and recall of movie content. These new comparisons might provide further information for predictions about working memory and dual-processing. In order to strengthen the claim that multiple-channel messages yield better comprehension, future studies must also include verbal-only conditions where participants are presented with either subtitle or soundtrack in the absence of pictorial information. It is suggested that the present study be replicated with different types of tests such as retention tests, matching tests and transfer tests as well as examination of male/female performances across different test types. Moreover, the study can be replicated with students of different proficiency levels or other age groups to investigate the differences between levels of comprehension with the same type of questions on other variables.

Additionally, the current study attempted to continue previous subtitling studies by investigating comprehension of documentary films in terms of verbal only information related to movie scenes. Other experiments can be done when non-verbal information is presented in the actual documentaries or movie clips. Studies can also be directed at the retention level of each modality or presentation channel to see if observers presented with information in two different modalities (soundtrack vs. subtitles) concurrently show greater retention of verbal content than observers receiving verbal information in a single-modality, or in a similar fashion, whether observers presented with pictorial information only as opposed to auditory information possess a greater understanding of the content in general. Still further studies can focus on whether differences in the content or genre of the films can make any difference. Research is also needed to address the issues of cognitive load and the role it may play in long term memory when listeners access both pictorial and written annotations. Research can also examine the recall of films in an aural mode rather than a written mode to determine how well listening comprehension and speaking interact. Individual variability can constitute another line of inquiry such that studies can examine the extent to which these effects are influenced by the individual learner's verbal ability (Plass et al., 2003) or his/her perceptual learning styles and strategies (Ehrman and Oxford, 1990; Oxford, 1990; Reid, 1995). Finally, the present study used an Ex post facto design in which subjects were assigned to different modality conditions. Although the use of such a design allowed for the examination of the effects of modality when learners were to learn the same stimuli under different conditions, it does not control for the differences in the results arising from individual differences. Another possibility is to use a within-group research design using similar groups of subjects in both conditions. However, care should be taken in the use of same-group designs because although such a design may control for individual differences, it may be susceptible to test-retest or repetition effects if the same group of subjects is tested repeatedly under different conditions.

\section{Pedagogical implications}

This study showed female viewers outperform their male counterparts in comprehending documentary texts. One importance of this finding can be for teachers and instructional designers in multimedia environment. If as Becker (2008) maintains, boys and girls differ in language processing and language development, the findings of the present researcher on superiority of female participants in processing both soundtracks and subtitles can be important for both teachers and parents. This is because the research helps teachers provide the best testing for the students. The teacher has to provide a testing method that caters for the boys' and girls' shortcomings in language processing. For example, during the testing process boys perform well when tested using the same sensory modality (Becker, 2008). 
When reading comprehension, boys will perform better if the teacher uses both visual and audio modalities. Using the two modalities when teaching helps the teacher ensure both boys and girls perform well. For example, in reading comprehension in an English class, the teacher will allow the student to read through the comprehension loudly. This will allow the teacher to use the auditory modality to support the students' shortcomings. Then after reading the compression loudly, the teacher will use visual modality whereby he will allow students to use visual modality (Becker, 2008).

If research can identify and better understand gender differences, then males and females can potentially approach situations in a way that best suits them. For example English teachers can engage students in receiving information in channels (audio and subtitles) which best suit their cognitive ability. Furthermore, since the viewer is considered as a limited capacity information processor, who should perform the task of encoding, processing, and storing the contents of the message and interact between a message content and structure and his own information processing system, the teacher or instructional designer can develop a working structure of auditory events with the primary purpose of helping students to control their attention in multimedia environment as they read and listen to multimedia.

Moreover, we can handle the issue of subtitled films in class with different modalities so that every individual with differing preferences can benefit from it. A related issue exists in cases where the viewer understands the language of the subtitles, but not the soundtrack. If viewers must rely on subtitles to comprehend the information from a movie or television program, then the observers must focus their visual attention strictly on the program.

This study also offers some implications for multimedia design. Multimedia environments that provide both pictorial and written modes of information may be most effective for learning because the students can choose the mode that best suits their needs and learning preferences. Future research is needed to examine issues related to the outcomes of these studies. For example, a more comparative approach to examining the connection between testing mode and presentation mode seems warranted.

\section{References}

Baddeley, A.D. (1986). Working memory. Oxford: Oxford University Press.

Baker, M. (1998). Routledge Encyclopedia of Translation Studies. Routledge.London.

Canning-Wilson, C. (2000). Practical aspects of using video in the foreign language classroom. The Internet TESL Journal, Vol VI № 11 Retrieved from http://iteslj.org/Articles/Canning-Video.htmlChang, S (2003) . The Effect of Metacognitive Strategy Training on the Second Language Listening Comprehension through the Use of Subtitles. http://catalog.digitalarchives.tw/item/00/4a/b0/08.html Or wwwlib.ntut.edu.tw/www/ntut/journal/36-1/A-13.pdf

Hinkin, M. (2009). Comprehension of multiple channel messages: Are subtitles more beneficial than soundtracks? [Online] Available: http://krex.kstate.edu/dspace/bitstream/2097/1679/1/MichaelHinkin2009.pdf (September 26, 2010)

Imanian, M (2004 ). Verbal and non verbal methods of testing receptive skills

Nourzadeh, A. (2005) On the Relationship between Iranian EFL Learners' Gender and their use of Reading Strategies at High Schools

Nassaji, H. (2004) Input Modality and Remembering Name-Referent Associations in Vocabulary Learning. Canadian Journal of Applied Linguistics (CJAL)/Revue canadienne de linguistique appliquée (RCLA), 7(1) Retrieved from http://www.aclacaal.org/Revue/vol-7-no1-art-nassaji.pdf

Ollagnier- Beldame, M. Encelle, B. \& Prié, Y. ( 2011 ) Video Enrichment: Design Issues and Pilot Studies on Perception and Usability

Perego, E. Del missier, F. Porta, M. \& Mosconi, M. (2010). The Cognitive Effectiveness of Subtitle Processing. Media Psychology, 13, 243-272. doi: 10.1080/15213269.2010.502873

Stewart, M. A. \& Pertusa, I. (2004), Gains to Language Learners from Viewing Target Language Closed-Captioned Films. Foreign Language Annals, 37, 438-442. doi: 10.1111/j.1944-9720.2004.tb02701.x

Winke, P. Gass, S. \& Sydornco, T. (2010). The Effects of Captioning Videos used for Foreign Language listening Activities. Language Learning \& Technology, 14(1), 65-866. Retrieved from http://lt.msu.edu/vol14num1/winkegasssydorenko.pdf. 